DIW BERLIN

Discussion Papers
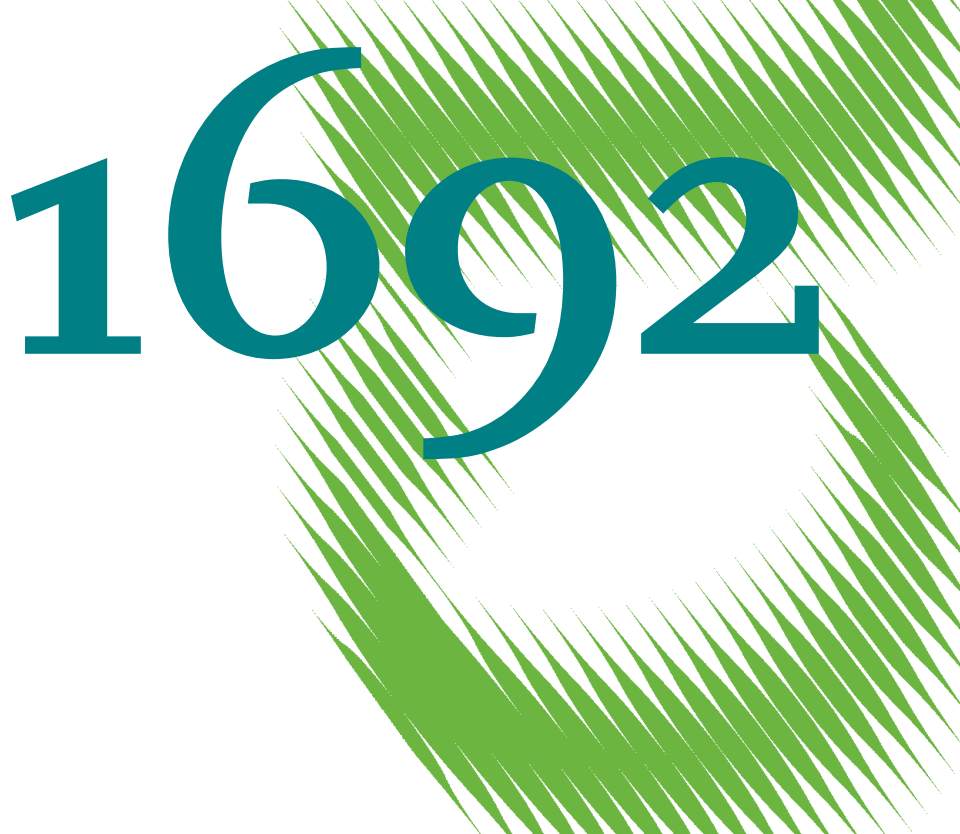

Employment and Human Capital Investment Intentions among Recent Refugees in Germany 
Opinions expressed in this paper are those of the author(s) and do not necessarily reflect views of the institute.

IMPRESSUM

(C) DIW Berlin, 2017

DIW Berlin

German Institute for Economic Research

Mohrenstr. 58

10117 Berlin

Tel. +49 (30) $89789-0$

Fax +49 (30) $89789-200$

http://www.diw.de

ISSN electronic edition 1619-4535

Papers can be downloaded free of charge from the DIW Berlin website:

http://www.diw.de/discussionpapers

Discussion Papers of DIW Berlin are indexed in RePEc and SSRN:

http://ideas.repec.org/s/diw/diwwpp.html

http://www.ssrn.com/link/DIW-Berlin-German-Inst-Econ-Res.html 


\title{
Employment and Human Capital Investment Intentions among Recent Refugees in Germany
}

\author{
Peter Haan ${ }^{1}$ \\ Martin Kroh ${ }^{2}$ \\ Kent Troutman ${ }^{3}$
}

Motivations to participate in the labour market as well as to invest in labour market skills are crucial for the successful integration of refugees. In this paper we use a unique dataset the IAB-BAMF-SOEP Refugee Survey, which is a representative longitudinal study of all refugees reported on administrative records in Germany - and analyse which determinants and characteristics are correlated with high motivation and intention to participate in the labour market. We find that overall men have a strong intention to work and to invest in human capital. The result for women is different: among women, having children, lack of German language skills, and having no previous work experience significantly and consistently correlate with lower expectations and intentions of future economic integration. Furthermore, we find a significant relationship between the degree of traditional or patriarchal views of women's societal roles, and our corresponding outcomes of interest.

JEL Codes: F22, J22, J24

Keywords: Refugees, labor market integration, human capital investment

\footnotetext{
${ }^{1}$ DIW Berlin and FU Berlin, phaan@diw.de

2 DIW Berlin and HU Berlin, mkroh@diw.de

${ }^{3}$ DIW Berlin and Princeton University, kentt@princeton.edu.

Kent Troutman thanks for the financial support by the Alexander von Humboldt Stiftung
} 



\section{Introduction}

The recent increase in refugees into Europe, and more specifically into Germany, has given new impetus to the important question of how to successfully integrate new residents into a nation's economy and society (Dumont et al. 2016, OECD 2016). The scale of the recent crisis, and the bleak outlook for its resolution, has motivated interest in the observed differentials in employment outcomes for refugees relative to both natives and other migrants.

Given the nature of the situation in many of the countries of origin, particularly Syria and Iraq, it must be considered that many refugees will remain in Germany for a long period. Thus, it is a priority for policymakers to make the integration process for the refugee population successful to avoid the many deleterious effects of being excluded from the national culture. Previous research has shown that successful labour market integration is the surest path to successful integration. However, many refugees find it difficult to participate on the labour market given the circumstances of their arrival, labour market restrictions and language barriers, to say nothing of the lack of training and work experience relative to most natives. These effects might reduce their intention to integrate into the labour market.

It is the aim of this article to understand which determinants and characteristics are correlated with a high motivation and intention to participate on the labour market (for previous research in the Netherlands, see Bakker et al. 2016 and De Vroome \& Van Tubergen 2010; for Germany, see Salikutluk et al. 2016; Brücker et al. 2016, and Krahn et al. 2000 for Canada)

In more detail, drawing on a unique dataset - the IAB-BAMF-SOEP Refugee Survey, which is a representative longitudinal study of all refugees reported on administrative records in Germany between 2013 and 2016 (Kroh et al. 2017) - we explore the intentions of recent refugees to Germany in terms of entering the labour market and making investments in human capital such as furthering education or obtaining recognition for previous experience/education.

Broadly, we find men have overall high-order intention to work and to invest in human capital: among men, we find that few covariates are significantly correlated with intentions, although having previous work experience and German language skills significantly raise their expectations of their success in the labour market. The result for women is different: among women, having children, lack of German language skills, and having no previous work experience significantly and consistently correlate with lower expectations/intentions of future economic integration. Furthermore, we find a significant relationship between the degree of traditional or patriarchal views of women's societal roles, and our corresponding outcomes of interest.

These findings suggest that further support and training - particularly in language acquisition - for refugees in joining the labour force, especially for those with little or no prior work experience, is important for increasing their motivation and thus ultimate success in finding employment or seeking outcome further training. Our results also suggest that policies must consider the low-order intentions to work and engage in further training for women by, for example, not pooling benefits across husband and wife such that only one partner need take integration / language courses, and also ensuring that adequate childcare is provided.

The remainder of the article will be structured as follows: section two provides more detail on the recent increase in refugees in Germany and provides an overview of the literature to which this article contributes; section three describes our data and the decisions we made regarding our 
sampling; section four reports our results; and section five concludes with a brief review and discussion.

\section{Background and summary of literature}

In Germany, after averaging between six and twelve thousand asylum applications each month for 2013 and 2014, in 2015 the number increased dramatically, as around 890,000 arrived (BMI 2016). A large share of these new arrivals originated from Syria, Iraq and Afghanistan, where violent conflict pushed people to flee to Europe - often via dangerous routes - in unprecedented numbers.

Although Germany has had previous experience with surges of refugees (notably during the Balkan conflicts - see the DIW Economic Bulletin 34 + 35 (2016) for more details), the scale, the uncertain resolution of the causal forces, and the relative cultural and human capital differences with the native population make this episode far more challenging. Indeed, according to the IAW-BAMF-SOEP Refugee Survey, around just $37 \%$ of adult respondents attended secondary school - which roughly equates to 12 years of education or university entry qualification - in their country of origin and just $32 \%$ graduated (note that we only use survey data of respondents 18+) (Brücker et al (2016)). Furthermore, one-third have never been employed and only about $20 \%$ claim to speak German proficiently.

Although Germany has some experience with immigration, it does not have the institutional experience with integration that comes with long histories of immigration that other developed countries such as the United States, United Kingdom, Australia, etc. have (see Dustmann and Frattini (2011)). Although the causes and near- and long-term consequences of this development have been speculated upon at length elsewhere (see IMF (2016)), it is certain that this will be a significant challenge for Germany.

A cornerstone of successful integration of migrants of any variety into their host country is early contact with the labour market (Lemaitre (2007)). Similarly, unemployment often leads to social exclusion and high rates of crime and detention (see Tranaes (2015) for a summary of the evidence). However, finding a job in the new host country is often fraught with difficulties with tight restrictions on access, skill mismatch, degree recognition, language, and others. The job search process for any migrant, and even natives, is challenging, but refugees often face the additional challenge of a perilous journey, traumatic experiences, and lengthy application processes. Refugees thus have historically demonstrated lower labour force attachment.

A special edition of the Nordic Economic Review focused on labour market experiences of refugees to three Nordic countries, the authors conclude that in all three country countries profiled, refugees exhibited lower labour force attachment, lower expected lifetime earnings, and higher social assistance dependence than low-skill natives and traditional migrants. According to these studies, which used mostly administrative data, refugees often showed slight improvements in their first decade along the aforementioned outcomes, but worsened thereafter. Women in particular showed very low labour force engagement which, although improved slightly with time, remained very low (see Schult-Nielsen (2017), Sarvimäki (2017), and Åslund et al (2017)).

Salikutluk, Giesecke, and Kroh (2016) show for refugees arriving in Germany between 1990 and 2010 that $65 \%$ of men were working and another $19 \%$ were unemployed - leading to $17 \%$ outside the labour force. For women, however, the authors report that just $51 \%$ of women are working and $13 \%$ 
are unemployed leading to $36 \%$ outside the labour force. These findings are in line with other studies which have documented the low labour force participation among refugee women (Worbs and Baraulina (2017) for Germany, see also Chiwick et al. 2004; Dustmann \& Fabbri 2003, Hartog \& Zorlu 2009).

Several studies have explored the marked difference in labour force engagement among women in Middle Eastern and North African countries - the countries of origin of most refugees in the Nordic studies and of those recently arrived in Germany. Dildar (2015) finds that traditional or patriarchal views are closely (negatively) associated with women's decision to find employment. Similarly, Hayo and Caris (2013) find that identities tied closely with religiosity are inversely correlated with female labour force participation. Moghadam (2013) proposes that in addition to the social factors, economic policy factors such as lack of health or childcare, inadequate worker protection against discrimination, and equal access to educational resource - while also acknowledging that cultural norms are likely causally linked to these phenomena as well.

Our focus on refugees' labour market integration, especially that of women, besides the concern about the detrimental effects on the individuals themselves, is further concerned about the intergenerational pass-through of non-integration, and the harm it does to life outcomes of the children and even grandchildren of migrants. A number of studies have shown that the degree of integration of parents (and the implied economic effects) has a large influence of the integration and labour market success of their children (see Papademetriou et al (2009), Heckmann (2008), Chiswick et al (2002)). As women are most often the primary caretakers and overseers of the education of children, especially in more traditional households which characterise the majority of the refugees in Germany, ensuring that they have a path to the labour market and thus a path to successful societal integration is very important.

Informed by the job search literature on planned behaviour, our study seeks to build on previous descriptive work on the recent group of refugees (see DIW Economic Bulletin 34+35 (2016)) and describe the labour market entry and training intentions of recent refugees in Germany and identify characteristics of high/low order intentions, and in so doing, indicate populations or characteristics that denote risk of labour force detachment.

\section{Data and sample}

We use the 2016 Sample of the IAW-BAMF-SOEP Refugee Survey, which is a representative longitudinal study of all refugees reported on administrative records in Germany between 2013 and 2016 (for details on the design and sampling see Kroh et al. 2017; for first findings, see Brücker et al. 2017). The survey covers a broad range of topics, including income, well-being, family structure, etc. Given that the survey should be repeated each year, those with an above average probability of receiving a positive application decision are overrepresented. This presents a challenge given that we don't get to see the applicants who arrived, for example, in 2014 and were rejected, and returned home in 2015.

A further issue for us is that we are measuring views about employment efforts and human capital investment decisions, which will likely be impacted by one's application status (see also, Zetter \& Ruaudel 2016). Although the German government passed several reform packages (namely Asylpaketen $1 \& 2$ ) to help high probability applicants gain labour market access during the application process, these rules were not in force for the majority of our sample. 
We deal with these issues by a) limiting our sample to those who have already received a decision, and b) limiting our sample further to groups with high rates of acceptance. Namely, we limit our sample to Syrians and Iraqis, who have acceptance rates of roughly $95 \%$ and $65 \%$, respectively. Of those, we restrict our sample to those with positive decisions ${ }^{4}$.

In Table 1, we show descriptive statistics and compare the outcomes between men and women, and between Iraqis and Syrians. While there are non-trivial differences between Syrians and Iraqis, notably in education and gender, the differences along key characteristics are insignificant. Between men and women, however, the differences are more marked. At the time of the survey, women were more likely to be married, to have children, to have been in Germany longer, to be college educated, and to be unemployed.

Key to our study, the survey contains a number of questions about respondents' intentions with respect to employment and education or retraining. We identified six outcomes that are relevant to our research question and have high response rates within our sample. These questions are asked in the following forms:

Q1: "How likely is that in the next year you will be employed?"

A1: 1 = "Definitely not" ... 4 = "Definitely so"

Q2: "When do you intend on being employed?"

A2: 1 = "At least more than 5 years" ... 4 = "As soon as possible"

Q3: "In the next 2 years, how likely is that you..." (this question is asked for four different outcomes)

1) “...find a job, 2) ...are self-employed, 3) ...go to school, 4) ...get further training?"

A3: 0 = "Extremely unlikely" ... $10=$ "Extremely likely"

In Table 2 as well as in Figure 1, we list the questions and summary information. In the extension of our analysis below where we focus on women's views, we also incorporate a number of values questions relating to women's role in the household, freedom, and about general satisfaction.

\section{Results}

In order to assess the relationship between low and high-order responses, we run a basic linear regression model on the ordered outcomes, controlling for the characteristics detailed in Table $1^{5}$.

Based on a priori views informed by the literature, we include regressions for the total population as well as split samples by men and women to capture the interactions of our covariates and gender. In

\footnotetext{
${ }^{4}$ We also considered including Afghans, given that those that are accepted are likely from areas which remain conflict zones, and that should theoretically be random and uncorrelated with other characteristics. We conducted our analysis with Afghans included and it did not change any of the results in any significant way. We opted, therefore, to forgo the extra observations in favour of the more conservative approach of excluding them because of possible non-randomness in sample.

${ }^{5}$ We also conducted this analysis using ordered probit and logit models, but the results did not meaningfully differ from those of the linear model. Therefore, for ease of interpretation and reporting, we show the linear results only.
} 
order to control for the effects of arriving at different times, we include cohort fixed effects, defined by calendar quarter and year of arrival.

Outcome 1: What is your future intention to be employed?

As shown above in Section 3, this question asks about when the respondent would like to start working, with responses ranging from "definitely yes" to "definitely no". This question most clearly addresses our core research concern: the intentions to enter the labour market. In this outcome we see a clear divergence between men and women. With the exception of German language skills, no covariate exhibits any statistical significance for males, and the constant is very close to the maximal value. For women, however, being over 30 , having children, having never been employed, and being Iraqi all exhibit very a strong negative relationship with intentions to work, whereas having a high school education, being healthy, and speaking German have opposite effects (see also De Vroome \& Van Tubergen 2010 for similar results on health effects).

\section{Outcome 2: When would you like to be employed? ${ }^{6}$}

In the survey, this question is asked directly after the question above. Responses range from "as soon as possible" to "in more than five years". Similar to Outcome 1, males show higher-order intention than females. However, having children, health, and lack of employment history are significant. For women, largely the same covariates are significant as in Outcome 1.

The big takeaway from these first two primary outcomes is that prior contact with the labour market matters a lot. For women's intentions on entering the work force (Outcome 1), lack of prior employment reduces their intention by two-thirds of a standard deviation, for the timing of their entry (Outcome 2), it's reduced by six-tenths of a standard deviation. Children also matter, especially for women. For men, it only appears to affect their estimation of the timing of their labour market entry. And contrary to what the findings of Worbs and Baraulina (2017) would suggest, the ability to speak German is and will continue to be significant, though the effect sizes are smaller.

Outcome 3: In the next two years, what is the likelihood that you find a job?

This is the first of a set of four likelihood questions which assess the respondents' perceived success in accomplishing a number of outcomes, with responses ranging from "not at all likely" to "extremely likely". In the survey, these are not asked after the previous two questions but in a separate section.

For this outcome, we see many of the same patterns present in the first two outcomes. Patterns of divergence between intentions and perceived success in outcomes becomes clearer. For both women and men, the presence of children is not significant, whereas it was very significant on previous responses. Health emerges as a much more significant factor, with effect sizes of between ten and fifteen percent of a standard deviation. German language skills are too very significant and the effect sizes are much larger as well. Prior contact has a similar effect as in previous outcomes for both women and men, in that prior work experience in very positively correlated with high-order response.

Outcome 4: In the next two years, what is the likelihood that you will be self-employed?

\footnotetext{
${ }^{6}$ We had some concern that this question would elicit non-responses from those who answered "definitely no" for Outcome 1 and would thus bias our results upward. This indeed turned out to be the case: all of the nonresponses from Outcome 2 who had responses in Outcome 1 had lowest-order responses (i.e. they responded that they definitely did not intend to work). For the missing responses to Outcome 2, we therefore keyed in low-order responses as well.
} 
Like the previous outcome, this value assesses the respondents' perceived likelihood of success, this time in becoming self-employed. Here again, for males, many of the covariates are orthogonal to the outcome, and have a drastically larger constant than women (four times larger). However, Iraqi men show a remarkably lower success perception than Syrians - around one-third of a standard deviation lower. And again, we observe significant negative relationship with lack of prior work experience.

For women, having children reduces the perceived likelihood of success by about one-third of a standard deviation. Iraqi women similarly to their male counterparts show lower-order responses of about one-fourth of a standard deviation.

Outcome 5: In the next two years, what is the likelihood that you will attend school?

This question assesses the respondents' perceived likelihood of attending school in the coming two years. Here the results differ from the preceding outcomes. For both men and women, we still see large negative effects of having children, two-thirds and two-fifths of a standard deviation, respectively. Age too seems to matter more than many of the previous outcomes. But previous work experience, health, and Iraqi origin, some of the more consistently significant covariates, show no significance. Importantly, German language skill remains important, underlining not only how critical it is for success, but that respondents are aware of its importance.

Outcome 6: In the next two years, what is the likelihood that you will obtain further job-related or other training?

This question is closely related to the previous one, except that it is worded such that it focuses on occupational training. The results are very similar, except that education and prior labour market contact is more significant. Puzzlingly, German language skill shows no significance at all, the only outcome for which it is insignificant. It's worth noting that, for males, the constant is the highest of any outcomes, indicating very high willingness / assessed likelihood of seeking out training.

\section{4b. Focus on Women}

Given stark differences in views expressed by women and motivated by other studies on the differential labour market outcomes for women in certain cultural contexts, we wanted to explore further the outcomes for women.

The context is that many countries in the Middle East and North Africa have very low female labour force participation, even after accounting for levels of development and other factors. As noted above in Section 2, several studies have explored the role of religious identity and traditional values in this phenomenon. Dildar (2015) provides a succinct overview of the issue of traditional patriarchal views' effects on women's labour participation using data from Turkey, and Hayo \& Caris (2013) provide useful nuance to the question of religion and identity as determinant factors in labour force decisions for women from the Middle East. We build on these studies, and exploit the battery of questions about religious and social views answered by respondents, as detailed in Section 3.

We include a set of regressions which include responses to five questions specifically about women's role in the work place and with respect to education investment choices in our baseline regression. In Table 2 we show summary statistics of each of these questions. There are some significant differences between the responses of men and women to these questions - about one-tenth of a standard deviation - with women answering more liberally than men. Interestingly, education for sons versus daughters is also the only values question where Iraqi's differ from Syrians, with Iraqis answering more liberally than Syrians. 
In Fehler! Verweisquelle konnte nicht gefunden werden., we show regressions which include the responses of female respondents to these questions ${ }^{7}$. The regression results show that the presence of children remains an important factor, although its significance in some cases was reduced. Prior contact to the labour market remains a very important explanatory factor. The views themselves show strong significance, though small effect sizes ranging from one- and two-tenths of a standard deviation.

It's difficult to discern the marginal impact of these views alone, as they are likely manifested in other ways such as fertility decisions (children in our model), prior labour force participation, marriage, and other decisions. That is to say, a woman who holds or whose family/household members hold traditional views of women are also more likely to have children, to have not entered the work force, to be married, etc.

\section{Discussion and conclusion}

In this analysis, we have described the labour market entry and human capital investment intentions among recently arrived refugees in Germany. We have found that, similar to previous findings of labour market participation of refugees in other developed countries and in their countries of origin, women and especially those with children show significantly less intention to enter the labour market. Men on the other hand, report high levels of willingness to entry the labour force and, especially among the young, willingness and intention to make education investments.

Our data do not allow us, however, to compare these intentions with regular migrants or natives, or indeed to match these intentions with eventual outcomes. These will be the subject of further research. However, we have established a clear pattern of high-order intentionality among men, and have described the characteristics of women that are associated with low-order intention.

Three results that stand out are the significance and size of the effects of having children, speaking German, having prior work experience, and health. In terms of policy implications, the strongly negative relationship between prior work experience and intentions to work signals the need to bring new refugee arrivals into contact with the labour market as soon as possible. A related study from Canada (Pandey and Townsend (2017)) shows that prior work experience in the host country significantly improves the outcomes for immigrants. The negative relationship with children, especially for women, indicates the need for a substantial amount of childcare support given to families that allow parents to look for and take up employment. The high-order responses from respondents with intermediate to high-level German language abilities demonstrate that it is critical to success in the labour market and efforts to improve these skills among refugees should continue. The results for health indicate a need bolster health care for refugees who are often coming from dangerous environments which can be deleterious not only physically but mentally. The social views question should caution policymakers when designing benefits, to ensure that they give women an equal incentive and opportunity to enter the workforce.

\footnotetext{
${ }^{7}$ We also ran the same analysis using the views of male members of the household, but the results did not differ meaningfully.
} 


\section{Bibliography}

Aiyar, S., Barkbu, B., Batini, N., Berger, H., Detragiache, E., Dizioli, A., ... Topalova, P. (2016). The Refugee Surge in Europe: Economic Challenges. IMF.

Åslund, O., Forslund, A., \& Liljeberg, L. (2017). Labor Market Integration of Refugees in Finland. Nordic Economic Policy Review, 115-158.

Bakker, L., Dagevos, J., \& Engbersen, G. (2016). Explaining the refugee gap: a longitudinal study on labour market participation of refugees in the Netherlands. Journal of Ethnic and Migration Studies, 43(11), 1-17.

Brücker, H., Rother, N., Schupp, J., von Gostomski, C. B., Böhm, A., Fendel, T., Friedrich, M., Giesselmann, M., Kosyakova, Y., Kroh, M., Kühne, S., Liebau, E., Richter, D., Romiti, A., Schacht, D., Scheible, J.A., Schmelzer, P., Siegert, M., Sirries, S., Trübswetter, P., \& Vallizadeh, E. (2016). Forced migration, arrival in Germany, and first steps toward integration. DIW Economic Bulletin, 6(48), 541-556.

Bundesministerium des Inneren (2016). 890.000 Asylsuchende im Jahr 2015. Press release from 30.09.2016.

Chiswick, B. R., Lee, Y. L., \& Miller, P. W. (n.d.). Family Matters: The Role of the Family in Immigrants Destination Language Acquisition. SSRN Electronic Journal.

Chiswick, B. R., Lee, Y. L., \& Miller, P. W. (2004). Immigrants' language skills: The Australian experience in a longitudinal survey. International Migration Review, 38(2), 611-654.

De Vroome, T., \& Van Tubergen, F. (2010). The Employment Experience of Refugees in the Netherlands. International Migration Review, 44(2), 376-403.

Cortes, K. E. (2004, 05). Are Refugees Different from Economic Immigrants? Some Empirical Evidence on the Heterogeneity of Immigrant Groups in the United States. Review of Economics and Statistics, 86(2), 465-480.

Dildar, Y. $(2015,12)$. Patriarchal Norms, Religion, and Female Labor Supply: Evidence from Turkey. World Development, 76, 40-61.

Dumont, J.-C., Liebig, T., Peschner, J., Tanay, F., \& Xenogiani, T. (2016). How are refugees faring on the labour market in Europe? European Commission \& OECD.

Dustmann, C., \& Fabbri, F. (2003). Language proficiency and labour market performance of immigrants in the UK. The Economic Journal, 113(489), 695-717.

Dustmann, C., \& Frattini, T. (2011). Immigration: The European Experience.

Frank Hansen, M., Schultz-Nielsen, M., \& Tranæs, T. (2017). The fiscal impact of immigration to welfare states of the Scandinavian type. Journal of Population Economics, 925-952.

Hartog, J., \& Zorlu, A. (2009). How important is homeland education for refugees' economic position in The Netherlands? Journal of Population Economics, 22(1), 219-246.

Hayo, B., \& Caris, T. $(2013,01)$. Female Labour Force Participation in the MENA Region: The Role of Identity. Review of Middle East Economics and Finance, 9(3), pp. 271-292.

Heckmann, F. (2008). Education and the Integration of Migrants. Brussels: EU Commission for Education and Culture.

Krahn, H., Derwing, T., Mulder, M., \& Wilkinson, L. (2000). Educated and underemployed: Refugee integration into the Canadian labour market. Journal of International Migration and Integration, 1(1), 59-84. 
Kroh, M., Kühne, S., Jacobsen, J., Siegers, R. \& Siegert, M. (2017). Sampling, Nonresponse, and Integrated Weighting of the 2016 IAB-BAMF-SOEP Refugee Survey. SOEP Survey Paper 2017.

Lemaitre, G. (2007). The Integration of Immigrants into the Labour Market. Paris: OECD.

Moghadam, V. M. (2013). Modernizing women: Gender and social change in the Middle East. Boulder: Lynne Rienner.

OECD (2016). How Are Refugees Faring on the Labour Market in Europe? A First Evaluation Based on the 2014 EU Labour Force Survey ad hoc Module. Working Paper 1/2016W.

Pandey, M., \& Townsend, J. (2017). Prior host-country work experience and immigrant labor market outcomes: evidence from Canada. IZA Journal of Migration.

Papademetriou, D. G., Sumption, M., \& Somerville, W. (2009). The Social Mobility of Immigrants and Their Children. Washington DC: Migration Policy Institute

Ruiz, I., \& Vargas-Silva, C. (2017). Are Refugees' Labour Market Outcomes Different from Those of Other Migrants? Evidence from the United Kingdom in the 2005-2007 Period. Population, Space and Place.

Salikutluk, Z., Giesecke, J., \& Kroh, M. (2016). Refugees entered the labor market later than other migrants. DIW Economic Bulletin, 6(34/35), 407-413.

Sarvimäki, M. (2017). Labor Market Integration of Refugees in Finland. Nordic Economic Policy Review, 91-114.

Tranaes, T. Active labor market policies and crime. IZA World of Labor 2015: 185 doi: 10.15185/izawol.185

Wanberg, C. R., Glomb, T. M., Song, Z., \& Sorenson, S. (2005). Job-Search Persistence During Unemployment: A 10-Wave Longitudinal Study. Journal of Applied Psychology, 90(3), 411430 .

Worbs , S., \& Baraulina, T. (2017). Refugee women in Germany: language, education and employment. Nuremberg: Bundesamt für Migration und Flüchtlinge

Zetter, R., \& Ruaudel, H. (2016). Refugees' right to work and access to labor markets-An assessment. KNOMAD Working Paper.

\section{Appendix}

Box 1: Theory of Planned Behaviour

A branch of the job search literature pioneered by Ajzen (1985) and recently carried forward by van Hooft et al (2005) and Wanberg et al (2005) states that an individual's behaviour depends directly on that individual's intentions of performing this behaviour. In turn, an individual's intentions are formed by two factors, subjective norms and attitudes towards the behaviour. Subjective norms include their own views about whether or not should perform the behaviour, and those of their family members, friends, spouses, etc. Attitudes towards the behaviour is broadly how the individual feels towards the behaviour, e.g. to what extent s/he enjoys the job search process.

In our analysis, we do not examine the hierarchical structure of intentions, but rather focus on the reported intentions themselves, since our research purpose here is in the eventual outcome - i.e. successful job placement or education investment. 
Table 1: Descriptive Statistics

\begin{tabular}{|c|c|c|c|c|c|c|c|}
\hline & \multirow{2}{*}{$\begin{array}{c}\text { ALL } \\
\text { Overall }\end{array}$} & \multicolumn{3}{|c|}{ GENDER } & \multicolumn{3}{|c|}{ COUNTRY OF ORIGIN } \\
\hline & & Female & Male & Diff & Iraqi & Syrian & Diff \\
\hline Male & $64 \%$ & $0 \%$ & $100 \%$ & -1.000 & $59 \%$ & $65 \%$ & $-0.064^{\star \star}$ \\
\hline$\%$ Married & $71 \%$ & $84 \%$ & $64 \%$ & $0.200^{\star \star \star}$ & $71 \%$ & $71 \%$ & -0.001 \\
\hline$\%$ with children & $63 \%$ & $77 \%$ & $55 \%$ & $0.222^{* * *}$ & $66 \%$ & $63 \%$ & 0.038 \\
\hline Household size & 1.7 & 1.8 & 1.6 & $0.218^{* \star *}$ & 1.6 & 1.7 & $-0.083^{\star}$ \\
\hline Age & 34.4 & 35.0 & 34.1 & $0.826^{*}$ & 34.2 & 34.5 & -0.249 \\
\hline$\%$ age $18-24$ & $20 \%$ & $15 \%$ & $24 \%$ & $-0.087^{\star \star \star}$ & $20 \%$ & $21 \%$ & -0.004 \\
\hline$\%$ age $25-30$ & $15 \%$ & $18 \%$ & $14 \%$ & $0.035^{* \star}$ & $18 \%$ & $15 \%$ & 0.029 \\
\hline$\%$ age $30-35$ & $18 \%$ & $22 \%$ & $16 \%$ & $0.057^{* * *}$ & $19 \%$ & $18 \%$ & 0.015 \\
\hline$\%$ age $35-40$ & $17 \%$ & $18 \%$ & $16 \%$ & 0.021 & $15 \%$ & $17 \%$ & -0.013 \\
\hline$\%$ age $40+$ & $30 \%$ & $28 \%$ & $31 \%$ & -0.025 & $27 \%$ & $30 \%$ & -0.027 \\
\hline Edu yrs & 10.2 & 10.1 & 10.3 & -0.188 & 9.7 & 10.3 & $-0.570^{\star \star \star}$ \\
\hline$\%$ edu high school & $55 \%$ & $55 \%$ & $54 \%$ & 0.009 & $58 \%$ & $54 \%$ & 0.036 \\
\hline$\%$ edu college & $15 \%$ & $19 \%$ & $13 \%$ & $0.062^{* * *}$ & $30 \%$ & $13 \%$ & $0.171^{* * *}$ \\
\hline$\%$ employed & $14 \%$ & $10 \%$ & $16 \%$ & $-0.061^{\star \star *}$ & $16 \%$ & $14 \%$ & 0.020 \\
\hline$\%$ subsidiary protection & $6 \%$ & $7 \%$ & $6 \%$ & 0.009 & $8 \%$ & $6 \%$ & 0.014 \\
\hline Time since arrival & 16.6 & 17.1 & 16.3 & $0.858^{* *}$ & 16.6 & 16.6 & 0.024 \\
\hline$\%$ Syrian & $87 \%$ & $85 \%$ & $88 \%$ & $-0.032^{\star \star}$ & $0 \%$ & $100 \%$ & -1.000 \\
\hline$\%$ Iraqi & $13 \%$ & $16 \%$ & $12 \%$ & $0.032^{\star \star}$ & $100 \%$ & $0 \%$ & 1.000 \\
\hline $\mathrm{N}$ & 2041 & 729 & 1312 & 2041 & 274 & 1767 & 2041 \\
\hline
\end{tabular}

$* * \star$ significant at $99 \%$ level

** significant at $95 \%$ level

* significant at $90 \%$ level 
Table 2: Descriptive statistics for outcome variables and social views

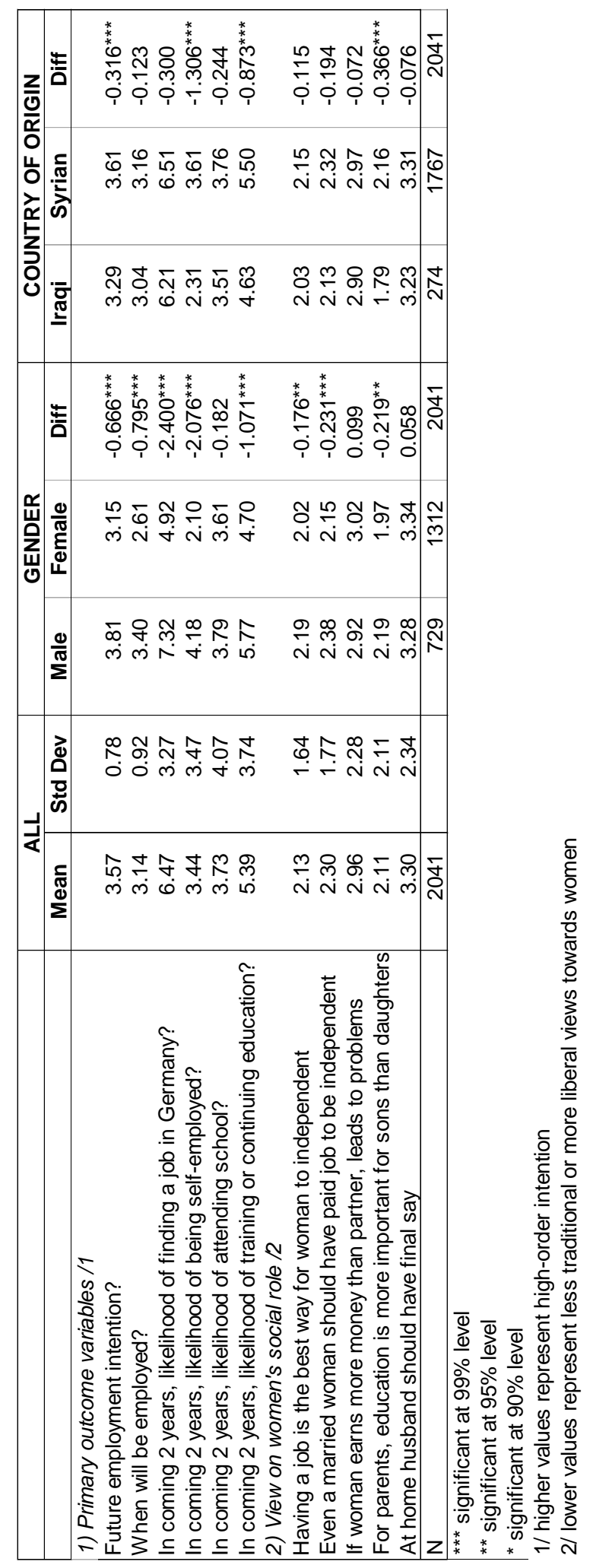


a.

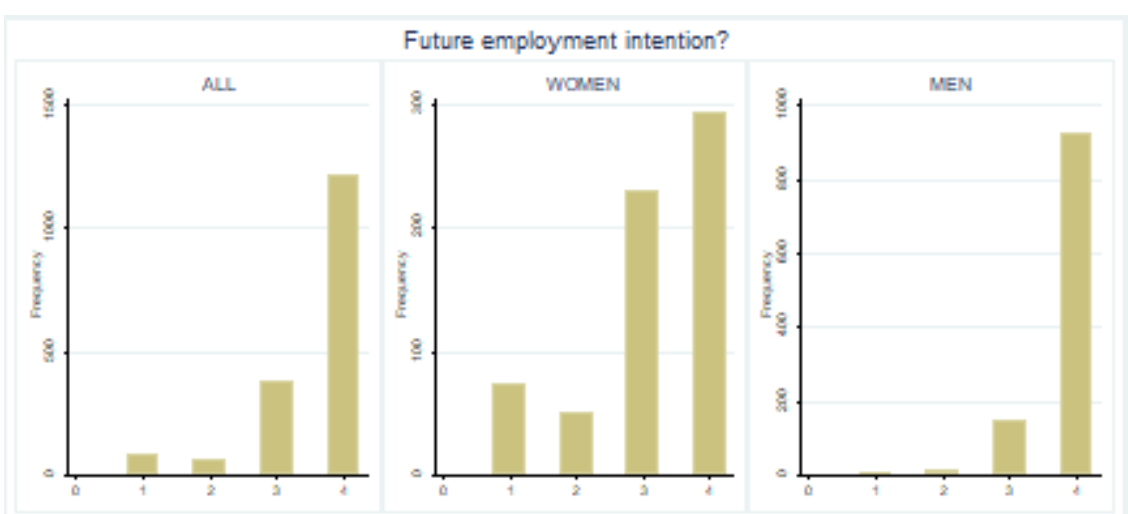

b.

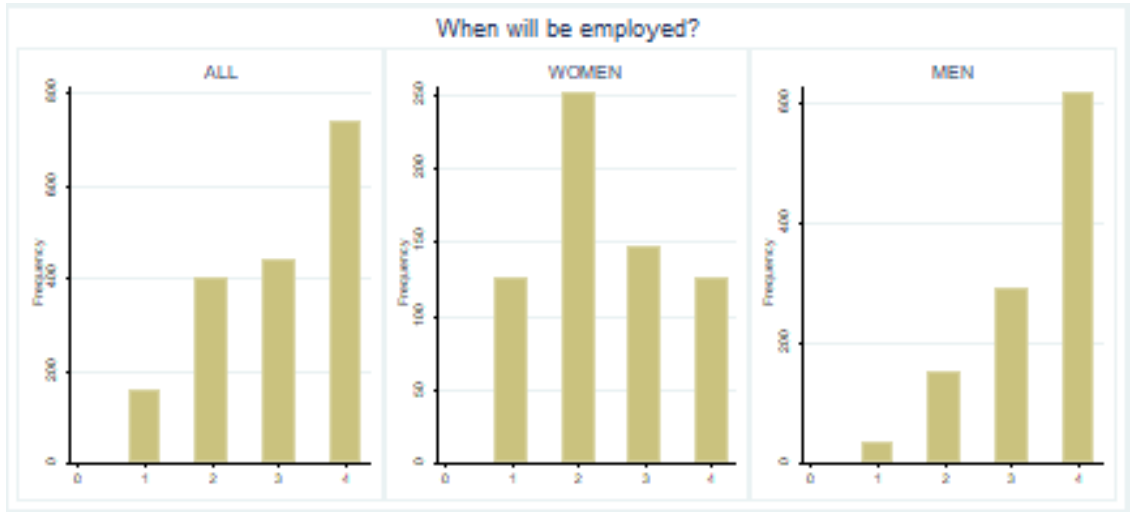

c.

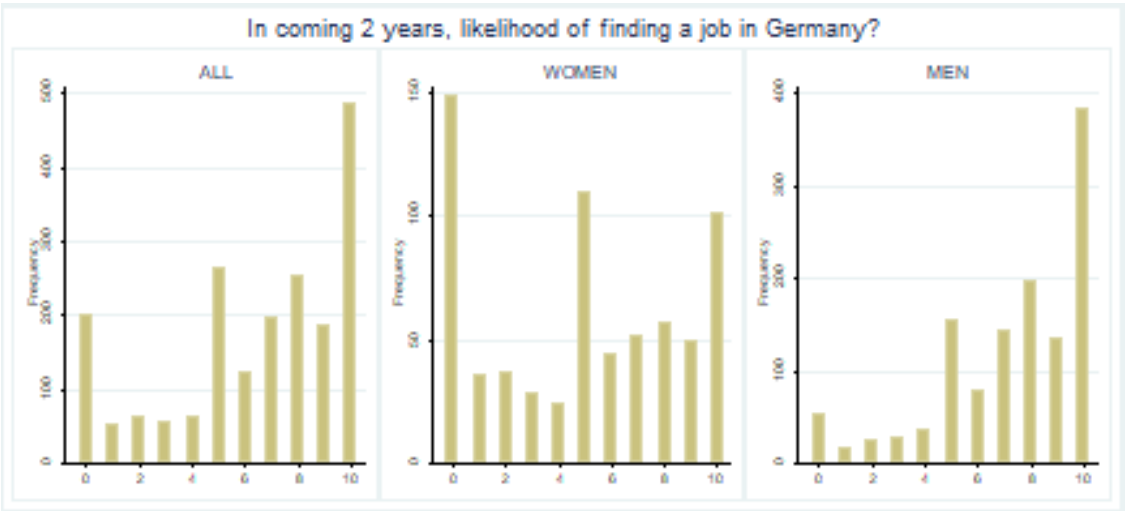

d. 


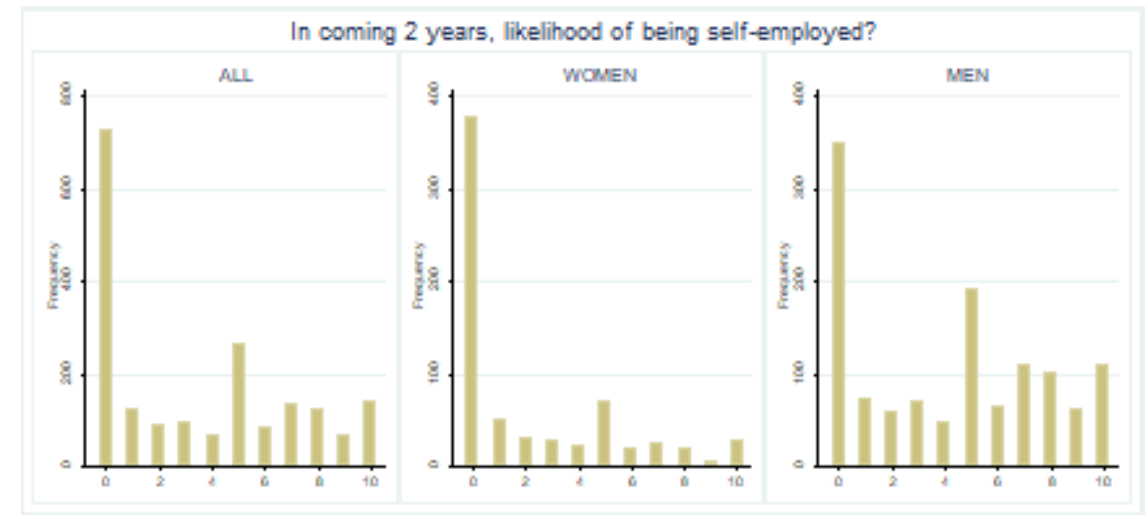

e.

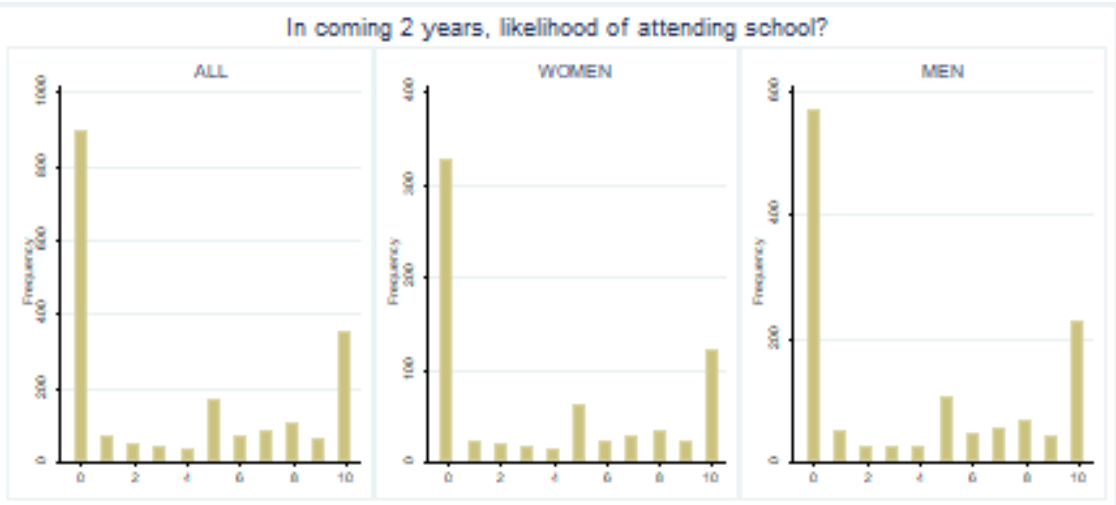

f.

In coming 2 years, likelihood of training or continuing education?

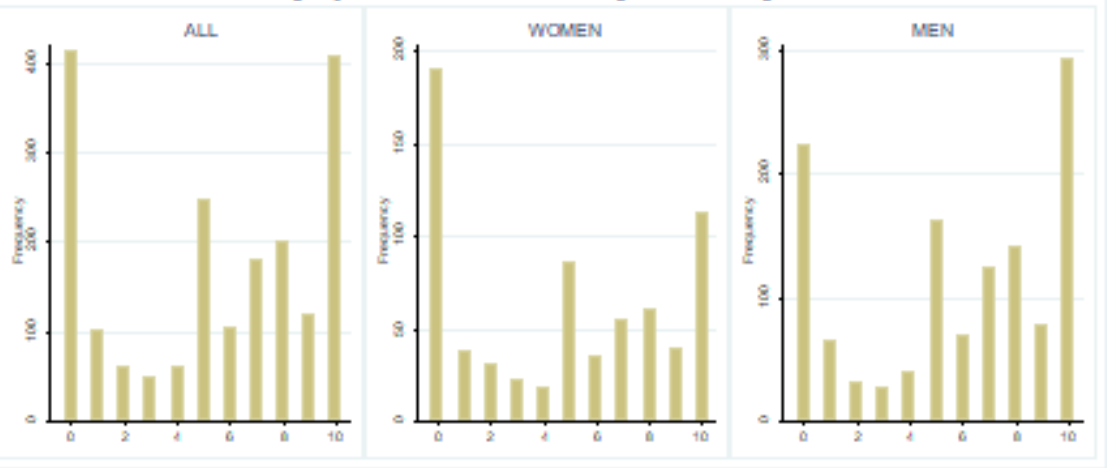


Table 3: Primary regression results

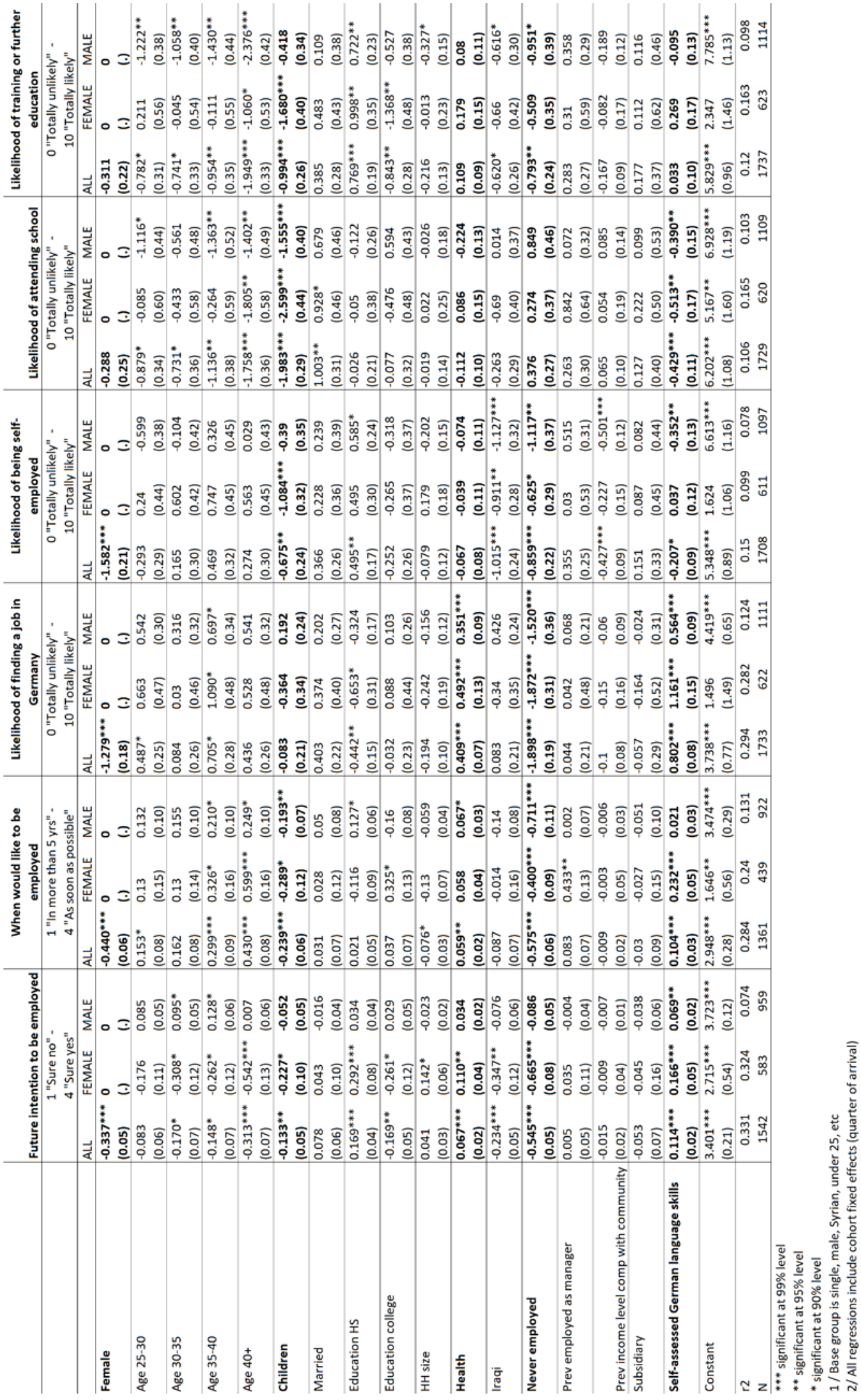




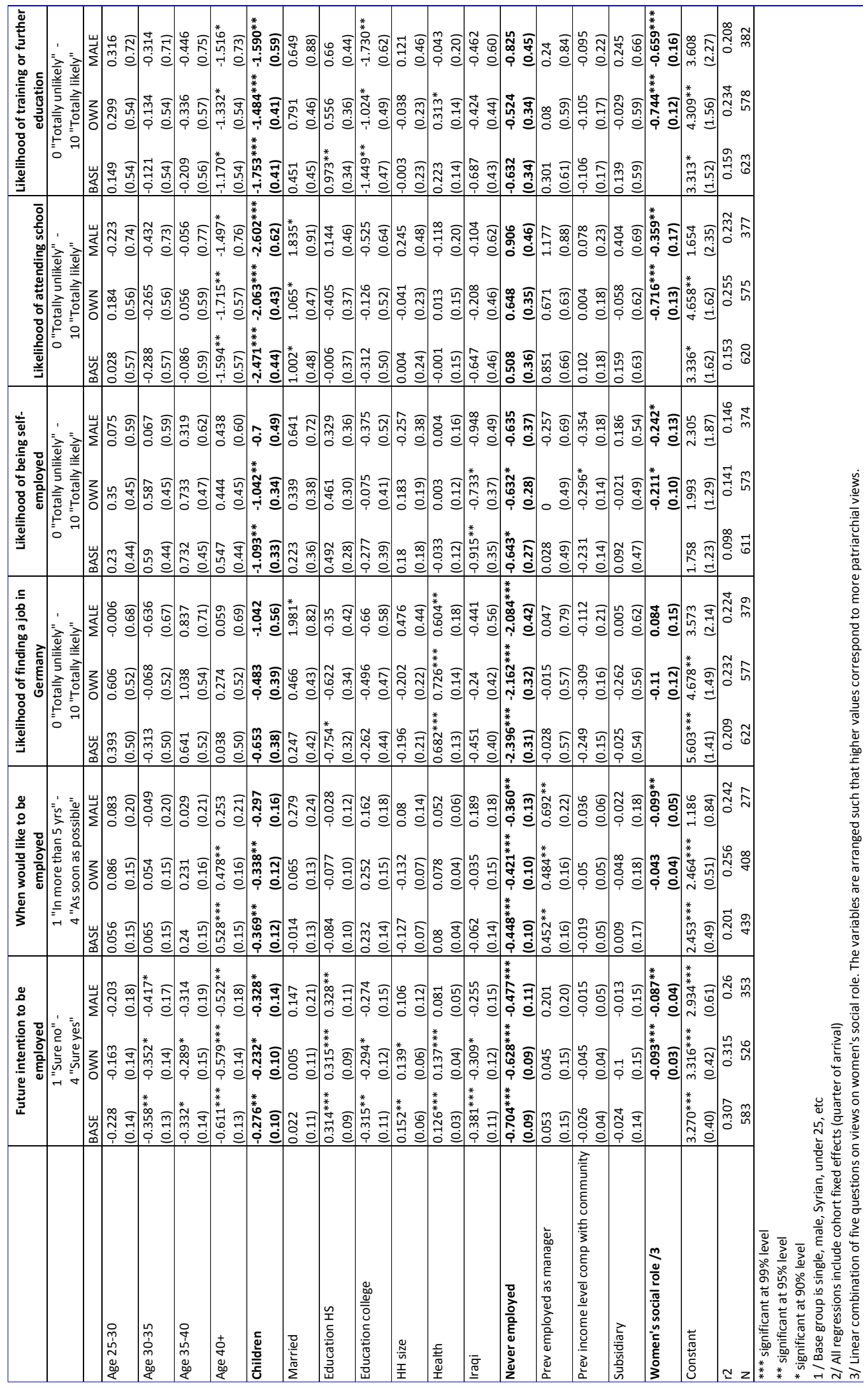

